\title{
USOS E POSSIBILIDADES METODOLÓGICAS PARA OS ESTUDOS QUALITATIVOS EM ADMINISTRAÇÃO: EXPLORANDO A ANÁLISE TEMÁTICA
}

\section{USES AND METHODOLOGICAL POSSIBILITIES FOR QUALITATIVE STUDIES IN ADMINISTRATION: EXPLORING THE THEMATIC ANALYSIS}

Recebido em 02.11.2019 Aprovado em 06.03.2020 Avaliado pelo sistema double blind review DOI: https://doi.org/10.12712/rpca.v14i1.38405

\section{Manuela Ramos da Silva}

mrs.gusmao@gmail.com

Programa de Pós-graduação em Administração/Universidade Federal de Sergipe (UFS) - São Cristóvão/SE, Brasil

ORCID: https://orcid.org/0000-0001-5739-6593

\section{Marcos Antônio de Souza Barbosa}

marcosasb@yahoo.com

Departamento de Administração/Universidade Federal de Sergipe (UFS) - Itabaiana/SE, Brasil ORCID: https://orcid.org/0000-0002-7225-5382

\section{Lucas Gabriel Bezerra Lima}

limalucasgabrielbezerra@gmail.com

Programa de Pós-graduação em Administração/Universidade Federal de Sergipe (UFS) - São Cristóvão/SE, Brasil

ORCID: https://orcid.org/0000-0003-2116-1850

\section{Resumo}

O objetivo deste artigo é apresentar a Análise Temática como técnica de análise científica de abordagem qualitativa e seu uso nas pesquisas em Administração. Para tanto, apresentam-se os caminhos de utilização e possibilidades metodológicas, a partir da discussão teórica baseada em autores como Alhojailan (2012), Braun e Clarke (2006), Cunliffe (2011), Vaismoradi et al. (2013) e King e Brooks (2017), assim como da exemplificação a partir de duas pesquisas que fizeram uso dessa técnica. Espera-se contribuir para o entendimento do que seja Análise Temática, oferecendo novas possibilidades de pesquisas qualitativas.

Palavras-chave: Análise temática. Pesquisa qualitativa. Administração.

\begin{abstract}
The objective of this article is to present the Thematic Analysis as a technique of scientific analysis of qualitative approach and its use in research in Administration. In order to do so, we present the ways of use and methodological possibilities, based on the theoretical discussion based on authors such as Alhojailan (2012), Braun and Clarke (2006), Cunliffe (2011), Vaismoradi et al. (2013) and King and Brooks (2017) as well as the exemplification from two researches that have used this technique. It is hoped to contribute to the understanding of what Thematic Analysis is, offering new possibilities for qualitative research.
\end{abstract}

Keywords: Thematic Analysis. Qualitative research. Administration. 


\section{Introdução}

Quando uma teoria se constrói ela se utiliza de questionamentos, contrapontos, análises e testes para validar suas teses, seus pontos de vista e sua base metodológica. É assim que Bachelard descreve esse processo a partir das barreiras intrínsecas ao ato de conhecer, as quais "podem ofuscar" o que realmente se deveria saber ou passar a conhecer (Bachelard, 2010).

Tecendo o desenho metodológico, cabe ao pesquisador definir o percurso mais adequado à sua linha de raciocínio objetivando a construção do conhecimento. Essa definição compreende uma conjugação de tipologias, abordagens, instrumentos e análises que descrevem, de modo preciso, o percurso adotado pelo investigador que melhor se adequa ao seu problema e objetivos.

Porém, a própria diversidade existente na classificação da pesquisa aponta para diferentes caminhos, sendo possível afirmar que um desenho metodológico nunca se repete, porque a cada investigação as escolhas são únicas e giram em torno de objetos que se analisam com base num conjunto de decisões que orientam a investigação de modo singular. Talvez por isso, pela diversidade de possibilidades, esse processo seja sempre cercado de dúvidas dos pesquisadores a respeito dos métodos a empregar, da escolha da pesquisa a ser empreendida e das técnicas e formas de coletar e analisar o material adotadas.

É tarefa do pesquisador, diante da base que fundamenta a pesquisa empírica, delinear sua metodologia da pesquisa, selecionando as possibilidades que melhor vão ajudá-lo a entender seu objeto de estudo e tratar sobre o problema que o cerca. Além desse conjunto de possibilidades, são também passíveis de escolha as técnicas de coleta e, por conseguinte, as técnicas de análise de dados, onde podem se localizar, dentre outras opções, a análise de conteúdo, a análise temática e a análise do discurso. Vergara (2010) considera importante alargar as opções metodológicas nos estudos organizacionais para novas possibilidades investigativas que saiam da orientação positivista, e que fundamentam a aplicação constante de métodos tradicionais de investigação, o que Marconi e Lakatos (2006) chamam de métodos de procedimento.

Em 1980, a Academy of Management Review publicou um artigo de referência de Gareth Morgan and Linda Smircich o qual apresentou um quadro situando métodos qualitativos dentro de suposições filosóficas mais amplas sobre a natureza da realidade e do conhecimento (Cunliffe, 2011). Os autores afirmaram que a colocação do método como a força motriz no trabalho empírico ignora o contexto mais amplo e mais profundo do conhecimento e da investigação social. Cunliffe (2011, p. 2, tradução nossa) comenta que: [...] Teoria em Organizações e Gestão (Organization and Management Theory OMT) tem se expandido para cobrir uma ampla gama de temas, incluindo o desenvolvimento de novas formas organizacionais (por exemplo, de rede e formas feministas); "reconceitualizando" cultura organizacional (como estética, estratificado ou simulacros); criticando formas normalizadas e ideológicas de gestão de organizações; examinando processos de organização, construção de identidade, narrando e resistindo; e concentrando-se em questões como a sustentabilidade, violência, raça, sexo e o corpo.

A Teoria em Organizações e Gestão também tem espelhado a evolução da teoria social, englobando interpretativismo, pós-estrutural e as formas criticamente informadas de teorização e pesquisa que incorpora uma infinidade de métodos qualitativos variando métodos narrativo, discursivo, psicanalítico e desconstrutivas. O esforço dos pesquisadores se concentra na construção de metodologias que atendam aos seus interesses de pesquisa, o que muitas vezes exige novas construções baseadas em elementos metodológicos de análise que permitam novos olhares para objetos já conhecidos da área, sem se deixar tomar por excessos: "Se a revisão da literatura revela muito, os leitores sentem que a teoria não emerge dos dados; se a revisão da literatura revela muito pouco, o projeto vai parecer muito amplo no escopo para ser administrável” (Basal \& Corley, 2012, p. 510).

É necessário que os dados interajam com a literatura de uma forma coordenada, em conjunto, mostrando que é uma produção autêntica e que faz sentido. Tracy (2010) apresenta oito marcadores de qualidade 
em pesquisa qualitativa: assunto autêntico, rigoroso, sinceridade, credibilidade, ressonância, contribuição significativa, ética e a coerência, que oferecem "um modelo pedagógico útil e fornece uma linguagem comum das melhores práticas qualitativas que podem ser reconhecidos como parte integrante de uma variedade de públicos" (Tracy, 2010, p. 840).

Os estudos qualitativos permitem oportunidades de desenvolvimento e aperfeiçoamento de métodos de investigação que se aplicam a diferentes ambientes, contextos, sujeitos e relações. Tais estudos também demandam seu próprio espaço de experimentação e testagem e sugerem a necessidade de interação entre os campos do conhecimento a partir da interdisciplinaridade no sentido de encontrar os caminhos mais adequados à análise e interpretação de fenômenos que se dão dentro e fora do ambiente das organizações, eminentemente dinâmico, contraditório e interativo.

Dito isto, observa-se que as práticas de pesquisa no campo da Administração vêm sendo desenhadas com o apoio de técnicas já consagradas na pesquisa social, mas também podem vir mescladas a métodos e técnicas que também se aplicam a outros campos, nesse sentido: parte da dificuldade em delinear o conceito indescritível de contribuição teórica é que estudos de organização e de gestão é um campo eclético - com múltiplas partes interessadas também. Não só se auto identificam como "tomadores" de muitas outras disciplinas científicas (por exemplo, psicologia, sociologia, economia, etc.), mas também afirmam falar para acadêmicos e profissionais (Corley \& Gioia, 2011, p. 12).

Nesse sentido, a questão norteadora que emerge é: quais as possibilidades da Análise Temática, como técnica de análise de dados, no processo de pesquisa qualitativa em Administração? Assim, o objetivo central deste artigo é apresentar a Análise Temática como uma técnica de análise científica de abordagem qualitativa e o seu uso, em particular, nas pesquisas no campo da Administração. Para tanto, apresentamse os caminhos de utilização e possibilidades metodológicas, a partir da discussão teórica baseada em autores como Alhojailan (2012), Braun e Clarke (2006), Cunliffe (2011), Vaismoradi et al. (2013) e King e Brooks (2017), assim como se discute os usos e suas possiblidade da AT para pesquisas qualitativas no campo da Administração, por meio de exemplos, como recurso metodológico, de duas pesquisas que fizeram uso dessa técnica .

Uma perspectiva multiparadigmática, implica na coexistência de diferentes modos de acesso e conceituação da realidade (Godoi \& Balsini, 2010). Essa multiplicidade de forma de compreender os fenômenos organizacionais atinge os enunciados ontológicos, epistemológicos, teóricos e metodológicos do pesquisador. Possivelmente em virtude desta amarração, a investigação qualitativa tenha se caracterizado tal como assinalam Denzin e Linconl (2000), primordialmente pelas tensões, contradições e vacilações. Segundo Godoi e Balsin (2010), a pesquisa qualitativa possibilita compreender o fenômeno social em sua complexidade; isto com o menor afastamento possível do cenário no qual esse fenômeno ocorre; ao que complementam: “[...] nesse cenário não se buscam regularidade, mas a compreensão dos agentes, daquilo que os levou singularmente a agir como agiram. Essa empreitada só é possível se os sujeitos forem ouvidos a partir da sua lógica e exposição de razões (Godoi \& Balsini, 2010, p. 91).

$\mathrm{Na}$ perspectiva qualitativa, as conclusões e os resultados de estudos e pesquisas podem ser localizados num espectro contínuo que vai da descrição à interpretação. Não há busca de regularidades, mas sim da compreensão dos agentes, do que os levou a agir e do como agiram, sendo interesse do pesquisador passar pela busca do significado e do sentido das ações e práticas que configuram a dinâmica social. Ao afirmarem que a pesquisa qualitativa possibilita a compreensão de processos ou fenômenos complexos, Godoi e Balsini (2010) advertem que esse tipo de pesquisa é uma espécie de conceito "guarda-chuva" por abranger formas variadas de pesquisa. 


\section{Breves notas metodológicas}

Dentre os diversos métodos, estratégias e técnicas de pesquisa que se caracterizam como qualitativas, aqui se destaca a Análise Temática como técnica de análise de dados. Visando ampliar e fortalecer iniciativas de estudos qualitativos sobre as organizações, este artigo tem como objetivo apresentar a análise temática como uma técnica de análise de dados e o seu uso em particular, nas pesquisas qualitativas no campo da Administração.

A compreensão dos fenômenos a partir das perspectivas dos participantes, a imersão de contexto, acolhem a técnica da análise temática como uma técnica de análise qualitativa, pois também parte do princípio de que o design da pesquisa não pode e nem precisa ser completamente especificado antes da pesquisa de campo (Godoi \& Balsini, 2010). Ressalta-se que o processo e o contexto constituem elementos inseparáveis do tema da pesquisa qualitativa, cuja ênfase está nos significados, sua descrição e interpretação, assim como na análise temática. (Alhojailan, 2012; Braun \& Clarke, 2006; Cunliffe, 2011; Vaismoradi et al., 2013).

A estratégia para elaboração deste artigo foi a de aproximação e utilização de uma técnica específica de análise com a finalidade de conhecer de perto sua operacionalização para, em seguida, situar seu uso nas pesquisas qualitativas. Será apresentado inicialmente o conceito de tema, assim como é discutida a análise temática como uma técnica de análise qualitativa. Também é feito um diálogo metodológico sobre a análise temática e as implicações de seu uso para os estudos em Administração. Ao final são apresentadas as considerações finais e as referências.

Para evidenciar o uso e as potencialidades da Análise Temática, tomou-se como passo inicial a compreensão sobre o que é um tema. Para Vaismoradi et al. (2016), tema é o principal produto de análise de dados fruto dos resultados práticos na área de estudo. Para os autores, o tema é usado como atributo, descritor, elemento e conceito. Em outras palavras, um tema organiza um grupo ideias e permite aos pesquisadores responder ao problema de pesquisa. Um tema contém códigos que têm pontos comuns e um alto grau de generalidade que unifica ideias sobre o assunto investigado.

Um tema representa um nível de resposta padrão ou significado dos dados que está relacionado com as questões de pesquisa. Para determinar o que pode ser considerado um tema, um dos caminhos é decidir pela sua prevalência. Isso não significa, necessariamente, a frequência com que um tema ocorre, mas sim a ocorrência em termos de espaço dentro de cada item de dados e em todo o conjunto de dados. O ideal é que o tema ocorra inúmeras vezes em todo o conjunto de dados, mas uma frequência mais elevada não significa necessariamente que o tema é mais importante para a compreensão dos dados.

A decisão de um pesquisador é a ferramenta chave para determinar quais os temas são importantes e cruciais. Em outras palavras, para Braun e Clarke (2006), tema é entendido como uma ideia que capta algo importante sobre os dados em relação à questão de pesquisa que representa um padrão nas respostas. Quando os pesquisadores levantam a perspectiva do participante a um nível abstrato de conceituação e buscam o significado subjacente nas palavras dos participantes, significado implícito ou tema surgem. (Braun \& Clarke, 2006; Vaismoradi et al., 2016). Em síntese, o propósito do tema é buscar a essência das experiências do participante, referindo-se a um nível mais implícito e abstrato, requerendo interpretação.

\section{Análise temática como uma técnica de análise qualitativa}

Braun e Clarke (2006) apresentam a Análise Temática como uma técnica de análise qualitativa caracterizada pela flexibilidade por ser essencialmente independente de uma teoria ou epistemologia específica e que pode ser aplicada com uma variedade de abordagens teóricas e epistemológicas. Além disso, as abordagens de análise temática podem ser usadas com conjuntos de dados de tamanhos variados e podem ser aplicadas a uma ampla gama de interesses e tópicos de pesquisa. Dependendo da forma particular de análise temática escolhida, ela pode ser usada a partir de várias perspectivas teóricas e, 
portanto, aplicada para responder de maneira útil a uma ampla gama de questões de pesquisa (King \& Brooks, 2017).

[...] Análise Temática não é apegada a qualquer arcabouço teórico pré-existente e, por conseguinte, ela pode ser utilizada em diferentes quadros teóricos (embora não todos), e pode ser usada para fazer coisas diferentes dentro deles. (Braun \& Clarke, 2006, p. 81)

Em um estudo comparativo, Vaismoradi et al. (2013) concluíram que no campo da pesquisa qualitativa existem coincidências entre Análise de Conteúdo e Análise Temática, como a manipulação de dados e busca de padrões e temas. Para além de uma discussão sobre possíveis diferenças ou vantagens, entendemos que o importante é o pesquisador buscar o meio de investigação e análise com maior coerência possível com os objetivos de sua pesquisa. Assim, ele pode decidir pela Análise Temática quando, ao invés de uma descrição detalhada do conjunto de dados, houver uma maior necessidade de interpretação de outros aspectos do campo, como, por exemplo, gestos e ações de pessoas observadas em um contexto particular, seguindo formas de análise de dados que se concentrem principalmente na identificação, organização e interpretação de temas em conjuntos textuais (King \& Brooks, 2017).

A Teoria Fundamentada, ou Grounded Theory (GT), é muito semelhante à Análise Temática no que se refere aos procedimentos de codificação de temas, mas para Alhojailan (2012) existe uma diferença a partir do principal instrumento da GT: a coleta e análise de dados que acontecem em processos paralelos, o que significa que a coleta adicional de dados deve se basear no que foi previamente analisado, ou seja, a GT depende da amostragem teórica determinada durante a coleta de dados.

O método de análise temática pode ser aplicado a conjuntos de dados qualitativos muito diferentes, desde narrativas em primeira pessoa, como em entrevistas de pesquisa tradicionais, até entrevistas em grupo maiores, talvez obtidas em ambientes de grupos focais, muito utilizado na área de administração, até fontes de dados secundárias, como recursos de mídia (King \& Brooks, 2017).

Assume-se que a Análise Temática é (mais uma) a possibilidade de uso de uma ferramenta de pesquisa flexível e útil, que pode fornecer uma rica, detalhada e também complexa análise de dados. Braun e Clarke (2006) trazem uma proposta de análise composta de seis fases e afirmam que o importante é justificar bem os usos, pois ao longo do processo de Análise Temática o pesquisador pode desenvolver ou flexibilizar instrumentos de análise para além daqueles apresentados. Destaca-se que uma etapa não precede obrigatoriamente a outra, tratando-se apenas de uma opção de como proceder a análise dos dados e sua representação. As seis fases da Análise Temática indicadas por Braun e Clarke (2006), são: 1) familiarização com os dados; 2) geração códigos iniciais; 3) busca de temas; 4) revisão de temas; 5) definição e nomeação de temas e 6) produção do relatório.

A literatura sobre análise temática geralmente se refere a "códigos" e "codificação", além de temas. Portanto, assim como estes autores, neste trabalho será adotado "código" para fazer referências a breves comentários ou abreviações vinculadas a passagens do texto para indicar material relevante para os objetivos da pesquisa, estes códigos podem ser desenvolvidos à medida que a análise prossegue nos temas (King \& Brooks, 2017)

King e Brooks (2017) analisaram a distinção entre formas genéricas e específicas de análise temática e estabeleceram princípios-chave para determinar e garantir a qualidade em uma variedade de abordagens de análise temática, passaremos a examinar a operacionalização de duas pesquisas com abordagens genéricas de análise temática usadas na pesquisa organizacional.

Para exemplificar, serão descritas a seguir duas pesquisas: Pesquisa aqui denominada "A" objetivou entender as razões do envolvimento ativista em Organizações Não-Governamentais Internacionais. A Pesquisa "B" teve como foco compreender a Escola Nacional de Administração Pública (ENAP), a partir da sua história organizacional, dos papéis desempenhados e das competências organizacionais desenvolvidas como escola de governo. 
A pesquisa A envolveu um trabalho interpretativo, observando o que havia de subjacente às respostas ditas dos entrevistados, trazendo impressões e ideias que não se tinha pensado, mesmo durante as primeiras formulações da tese. Já a pesquisa B seguiu um caminho analítico-interpretativo "dirigido pelos dados" na busca de temas que ajudassem a compreender a escola de governo quanto aos seus papéis, assim como suas competências organizacionais. Tal escolha possibilitou também a identificação de temas como contribuição na revisão do conceito de escola de governo, a partir da experiência e da história da escola de governo pesquisada.

$\mathrm{Na}$ análise dos dados e na redação do texto, optou-se por organizar a investigação a partir de temas que emergiram de todo o corpo empírico da pesquisa. As falas e as narrativas dos sujeitos da pesquisa formam esse corpo empírico e foram tratadas para contextualizar e trazer um significado para os temas. Logo, decidiu-se por priorizar o sentido e o significado dos temas que surgiram do corpus como um todo, ao invés de particularizar e identificar cada fala e seu respectivo autor. Isto implica a questão de abranger o significado de 'tema'.

De acordo com King e Horrocks (2010), tema pode ser definido como características recorrentes e distintivas das narrativas dos participantes, caracterizando percepções e/ou experiências particulares, que o pesquisador considera relevante para a questão de pesquisa. Desta forma, King e Brooks (2017) abordam que a análise temática refere-se as formas de análise qualitativa de dados que se concentram principalmente na identificação, organização e interpretação de temas em dados textuais. Eles se referem a 'formas', no plural, pois acreditam que não é um método único, mas uma abordagem ampla que engloba muitas perspectivas diferentes.

Quanto às fases propostas Braun e Clarke (2006), registra-se que no primeiro momento das pesquisas $\mathrm{A}$ e B, a Análise Temática iniciou a partir das diversas leituras dos textos (transcrições, observações de campo). Estes foram tomados um a um, sujeito por sujeito, narrativa por narrativa, no intuito de um "mergulho profundo" em cada história individualmente e, assim, tentar entender como cada um descreve o que a escola de governo é e o que a escola de governo faz (Pesquisa B). Na pesquisa A tudo foi relido de uma forma ativa, à procura de significados, inclusive das outras informações que não foram emitidas pelas falas, mas que pareciam chamar a atenção e mostrar que outros dados estavam dispostos ali a partir de acontecimentos durante as entrevistas e reações dos entrevistados. Nesta fase, preocupou-se que o mergulho chegasse até o "nível latente" das experiências do participante na busca do significado subjacente das palavras, o seu significado implícito (Braun \& Clarke, 2006; Vaismoradi et al., 2016).

No segundo momento da Pesquisa A foram gerados os códigos iniciais a partir das narrativas transcritas os quais identificaram uma característica dos dados e deram origem aos temas, à unidade de análise principal e mais ampla. Decidiu-se por uma codificação mais dirigida aos dados já na tentativa de identificar os sentidos comuns entre as entrevistas. 
Figura 1 - Códigos Iniciais da Pesquisa B

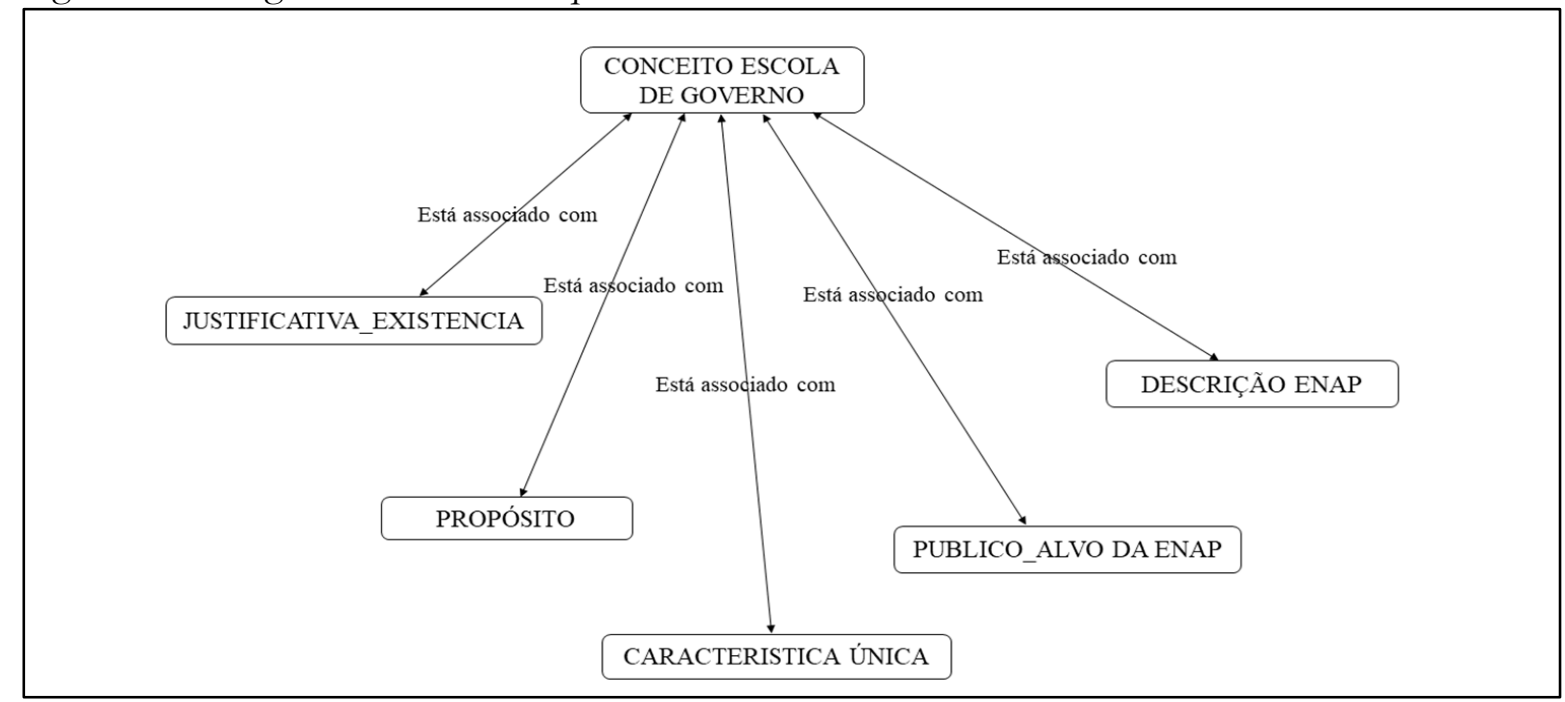

Fonte: Elaborado pelos autores (2020)

Conforme a Figura 1, na pesquisa B os códigos iniciais serviram para descrever a escola de governo pesquisada e os seus principais propósitos. Avançou-se para a análise dos marcos históricos, no esforço de compreender a influência do contexto político, principalmente, das reformas administrativas na história da organização estudada, dos seus papéis e objetivos. Importante dizer que muitos códigos foram gerados, e nas releituras que se seguiram até o final da análise, muitos foram excluídos e alguns redefinidos na tentativa de identificar os temas com prevalência e que emergiam da coleta e análise dos dados. Ainda na pesquisa B o programa Atlas TI foi utilizado como tecnologia de apoio e as notas de análise foram editadas de modo a sistematizar textos explicativos e descritivos associados aos códigos, às citações, etc., constituindo-se em um "lugar" para armazenar e tomar notas metodológicas e/ou teóricas, além de possibilitar uma relação entre os códigos e/ou ideias.

A Pesquisa A foi dirigida mais à teoria e nesse tipo pode-se utilizar um documento para cada entrevista contendo tabelas para extração de dados com perguntas e conceitos para relacionar com códigos que levaram aos temas, seguindo o seguinte modelo:

Quadro 1 - Extratos por entrevistado

\begin{tabular}{|l|l|}
\hline $\begin{array}{l}\text { Perguntas específicas em mente (baseadas na questão de pesquisa) que se } \\
\text { deseja codificar ao redor. }\end{array}$ & $\begin{array}{l}\text { Comentários que levam a códigos e } \\
\text { que levarão a temas }\end{array}$ \\
\hline Extrato de dados & \\
\hline
\end{tabular}

Fonte: Elaborado pelos autores (2020)

Esse documento também continha um espaço para considerações livres do pesquisador relacionadas a: a) Questões específicas por entrevistado; b) Um breve perfil do entrevistado; c) Considerações gerais; d) Ambientação, f) Impressão geral do entrevistado. Havia também um espaço específico para questões e insights que emergiram.

No terceiro momento, o objetivo foi a busca de temas que possibilitassem identificar as principais competências organizacionais daquela escola de governo (pesquisa B), a partir da narrativa sobre o que a organização faz como diferencial da sua atuação, quais características são difíceis de serem adquiridas, imitadas ou substituídas, quais os aspectos mais valorizados por quem busca ou necessita dos serviços da Escola e as justificativas para a sua existência e continuidade. Nesse momento citações diretas podem ser feitas, mas é bom ter em mente que o objetivo ainda não é ilustrar os códigos e temas, e sim deixar emergir ideias que favoreçam e justifiquem temas. Para fins deste artigo, a operacionalização da análise temática será focada na discussão sobre o conceito de escola de governo realizada por Silva (2017) durante o desenvolvimento da Pesquisa B, conforme é apresentado na Figura 2. 
Figura 2 - Identificação de temas para a compreensão de um conceito - Pesquisa B

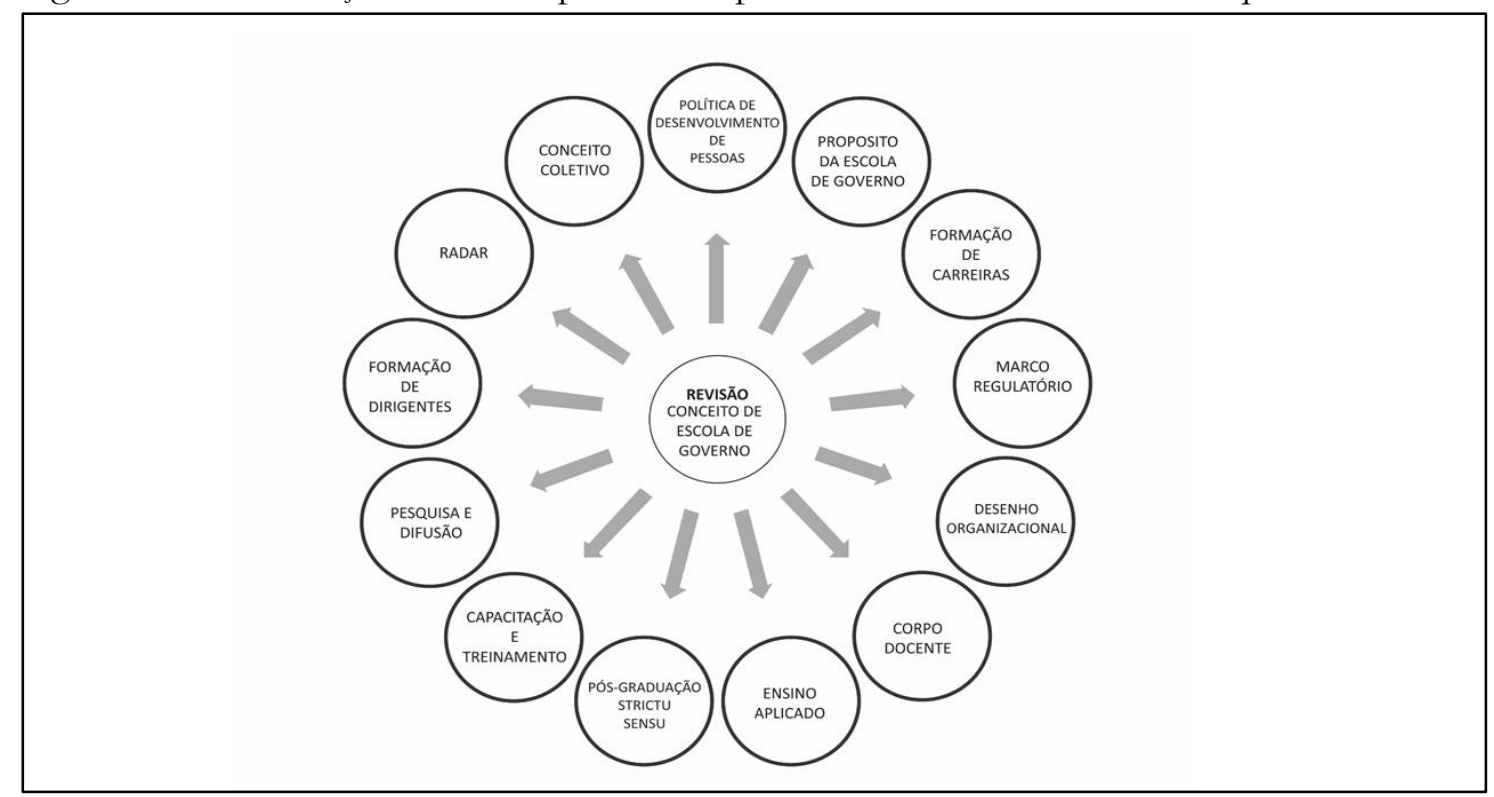

Fonte: Elaborado pelos autores (2020)

Por isso, quando da releitura dos extratos para essa fase e a fase anterior, é importante destacar trechos. Braun e Clarke (2006) sugerem a criação de mapas conceituais, estratégia utilizada nesta pesquisa. Aqui é importante tomar cuidado para não estar fazendo suposições e a partir delas buscar trechos nas entrevistas que atestem tais ideias.

A Análise Temática pede que temas sejam levantados, não especulações sejam postas e validadas. Nesse momento o importante é ter a questão de pesquisa e os objetivos sempre em vista e partir deles deixar emergir ideias autênticas, sem se perder nas falas dos entrevistados. Nesta fase, conforme alerta Braun e Clarke (2006), afasta-se das perguntas e dos pontos roteiros, com intento de chegar cada vez mais perto dos relatos colhidos. Isto foi possível, na Pesquisa B, com as idas, vindas e retornos à Fase 1, nas releituras das transcrições e do diário de campo. Assim, a descrição torna-se cada vez mais rica e a interpretação vai sendo (re)construída e novas pistas auxiliam na busca dos temas e/ou subtemas a partir da prevalência dos dados. Já na Pesquisa A, a volta aos extratos permitiu outro entendimento do que foi dito pelos entrevistados e novas relações se tornaram possíveis viabilizando, assim, novas descobertas. Braun e Clarke (2006) sugerem a criação de mapas conceituais, mas foi utilizado um documento chamado "O grande diferencial - Quais temas emergiram", onde foram feitas anotações livres que justificariam cada possível tema.

De lado ter uma quantidade razoável de entrevistas importa porque a leitura das transcrições e extratos repetidas vezes é um trabalho lento, que pede atenção e reflexão. O método utilizado não estabelece nenhum parâmetro quantitativo de entrevistados. Por outro lado, pode existir a sensação de não ter explorado mais os depoimentos e isso acontece porque no momento da pesquisa outras possibilidades de descobertas surgem, porém o que interessa é o surgimento de temas importantes ligados às questões e aos objetivos da pesquisa. Alguns parecem se confundir. Na investigação B o compreender como cada competência foi formada e/ou desenvolvida ao longo do tempo foi abandonada, devido ao redesenho dos objetivos iniciais da pesquisa e ausência de subsídios nas narrativas dos sujeitos que evitaram relatar fatos que ocorreram fora do período em que permaneceram na organização, dificultando uma análise da trajetória do processo de formação e desenvolvimento das competências organizacionais ao longo do tempo

Na quarta fase, a revisão dos temas provocou uma nova organização dos marcos teóricos da escola de governo e um esforço de análise e interpretação para que as competências organizacionais identificadas 
pudessem desenvolver uma autonomia de conteúdo que verdadeiramente contribuísse com a análise da história organizacional da pesquisa B. Enquanto que no final desta fase na pesquisa A, teve-se uma ideia do que são, de como se encaixam, bem como da história geral do que dizem sobre os dados. Os temas selecionados foram esses apresentados na Figura 3:

Figura 3 - Temas que emergiram

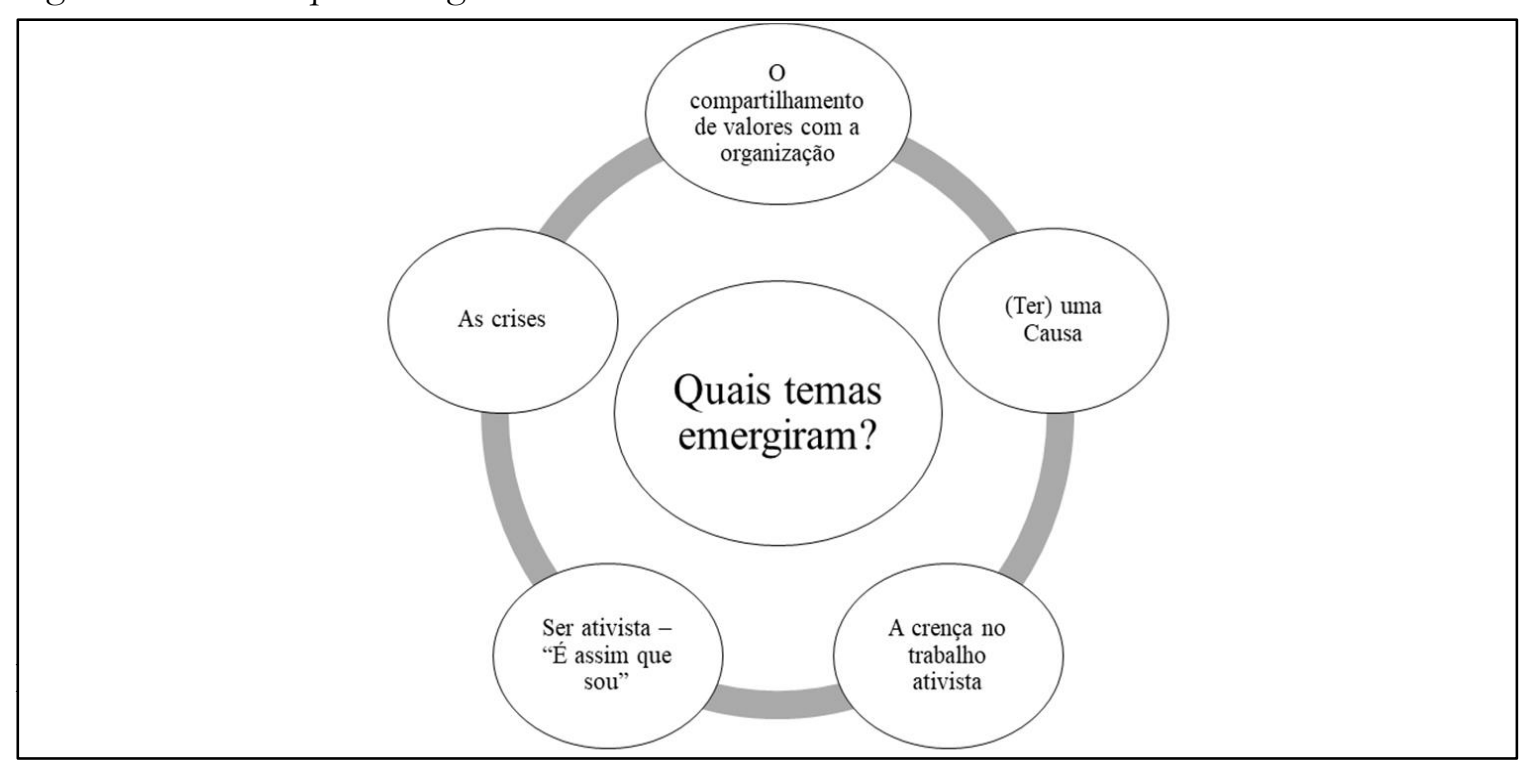

Fonte: Elaborado pelos autores (2020)

Nesta fase as releituras dos extratos dos dados, na Pesquisa B, tiveram um papel importante, com o auxílio do Atlas.ti , como demonstrado na Figura 4. Uma limitação desta pesquisa refere-se a não busca de subtemas para compor a identificação dos temas (principais) e de estabelecer relações e níveis entre os temas, assim como empreendido por Gross (2013).

Figura 4 - Revisando o Conceito de Escola de Governo - Pesquisa B

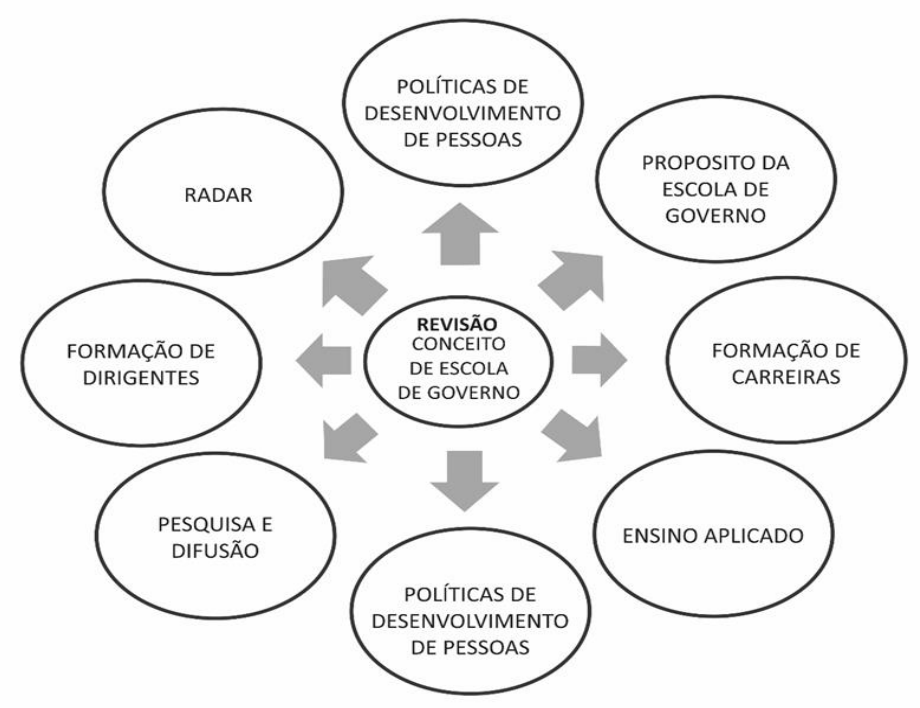

Fonte: Elaborado pelos autores (2020)

Braun e Clarke (2006) afirmam identificar a "essência" do que cada tema é (bem como os temas globais) e determinar que aspecto dos dados cada tema captura. É importante não tentar obter um tema para fazer muito ou ser muito diverso e complexo. É possível fazer isso indo de volta para extrações de dados recolhidos para cada tema e organizando-os em um quadro coerente e internamente consistente com acompanhamento da narrativa. 
É vital não apenas parafrasear o conteúdo das extrações de dados apresentados, mas identificar o que é de interesse sobre eles e por quê. Para cada tema, individualmente, é preciso realizar e escrever uma análise detalhada, bem como identificar a "história" que cada tema traz, considerando como ele se encaixa na "história" global que está sendo dita sobre os dados, em relação à questão ou questões de pesquisa, para garantir que não há sobreposição demais entre temas. Por isso é necessário considerar os próprios temas e cada tema em relação aos outros (Braun \& Clarke, 2006).

O quinto momento culminou na análise das competências organizacionais da escola de governo e dos seus elementos constitutivos e a análise dos temas centrais para a discussão conceitual de Escola de Governo na pesquisa B, possibilitando assim a ENAP juntamente com as demais Escolas que compõem a Rede de Escolas de Governo se aprofundaram na discussão e no debate em torna das questões "o que somos?" e "o que fazemos?". Os temas para revisão sobre o conceito de Escola de governo emergiram no processo de descrição da história organizacional da ENAP como Escola de governo ao longo de seus 30 anos, conforme a Figura 5.

Figura 5 - Temas para revisão conceitual Escola de Governo

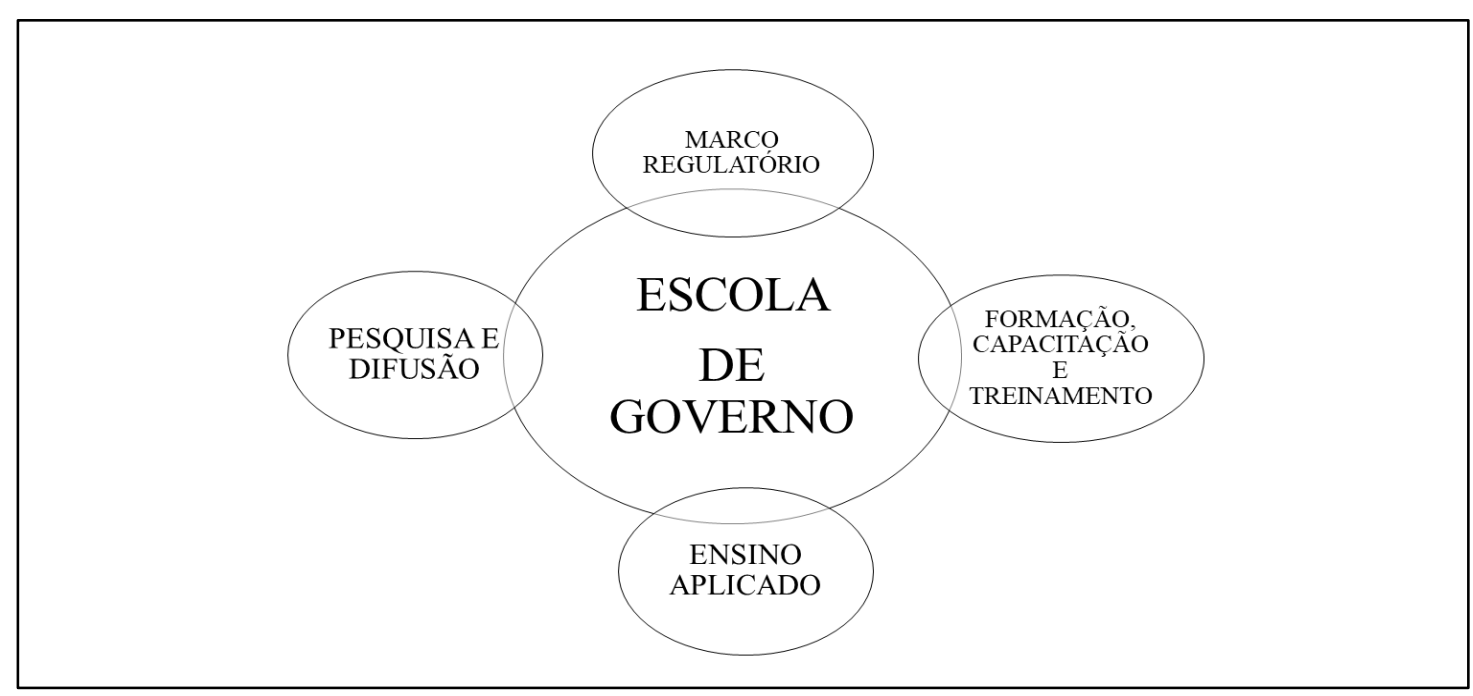

Fonte: Elaborado pelos autores (2020)

Para Vizeu (2010), o uso da perspectiva histórica na construção do conhecimento sobre a gestão e a organização brasileiras pode ocorrer mediante a adoção de um quadro teórico-conceitual constituído a partir da análise histórica ou mesmo pela aplicação da pesquisa histórica enquanto método de análise empírica e analítica.

$\mathrm{Na}$ pesquisa $\mathrm{A}$, as escolhas dos ativistas construíram afirmações que se encaixaram na relação entre objetivos gerais e específicos da tese e possíveis descobertas advindas do trabalho de campo.

Na sexta e última fase um "enredo" foi escrito para apresentar esse processo de análise de dados que se constitui numa interpretação de como é escola de governo, ao longo dos 30 anos, no caso da pesquisa B. Nesta história as falas e as narrativas dos sujeitos da pesquisa formaram o corpo empírico e foram tratadas para contextualizar e trazer um significado para os temas. Decidiu-se por priorizar o sentido e o significado dos temas que surgiram do corpus como um todo, ao invés de particularizar e identificar cada fala e seu respectivo autor.

No processo de análise de informações, na Pesquisa B. manteve-se a revisão de literatura em suspenso. Embora o engajamento com a literatura existente antes do levantamento de informações seja característica de uma parte significativa dos métodos qualitativos, é fortemente sugerido pelos autores Braun e Clarke (2006), Godoi e Balsini (2010), Deslauriers e Kérisit (2012) que a revisão da literatura em 
profundidade seja adiada até que o levantamento da maioria das informações seja concluído para evitar introdução de preconceitos e noções percebidas. Hoje reconhece-se que a riqueza desse momento indutivo da pesquisa, bem como das idas e vindas ao campo e à literatura.

O diálogo teórico-empírico permitiu retomar a revisão de literatura inicial, explorando-a e ampliando-a para dialogar com a empiria, que neste caso é a discussão do conceito de Escola de governo. As falas e os relatos apresentam uma narrativa e uma história coerentes, nas quais os temas estão descritos e, esperase que, conectados.

Enquanto que na pesquisa A foi utilizado um quadro de análise consolidada que ia sendo preenchido e modificado à medida que a escrita ia se aprofundando. Nesse momento os atores participaram ativamente na construção coletiva do texto. Suas falas e relatos apresentam uma narrativa e uma história coerentes, nas quais os temas estão descritos e conectados. É importante que a análise (o relatório do mesmo, incluindo extratos de dados) forneça um relato conciso e coerente, lógico, não repetitivo e interessante da história que os dados contam - dentro e através de temas, pois o relatório deve fornecer provas suficientes dos temas dentro dos dados (Braun \& Clarke, 2006, p. 93). O objetivo do texto final da análise dos dados a partir da Análise Temática é contar a história de seus dados de uma forma que convença o leitor da confiabilidade e validade de sua análise.

Por fim, dentro do seu caráter qualitativo, reflexivo, fenomenológico, subjetivista e dedutivo de construção do conhecimento assumido na pesquisa A e assim, longe de conclusões deterministas e classificatórias, os dados qualitativos consolidados serviram de pano de fundo da discussão teórica que se seguiu. $\mathrm{Na}$ Pesquisa B, identificaram-se que os aspectos da teoria e da empiria se constituíram em um diálogo-teórico-empírico, o qual retomou a revisão de literatura inicial, explorando-a e ampliando-a para dialogar com os achados que emergiram dos dados.

No caso deste artigo propiciou a discussão sobre o conceito de Escola de governo, a partir da experiência da ENAP, a partir uma codificação mais dirigida aos dados, identificando os sentidos comuns entre as entrevistas. Registra-se que na pesquisa $\mathrm{B}$ a análise temática contribui para o desenvolvimento de pesquisas de cunho histórico e interpretativista (Gross, 2013; Silva, 2017) pois a falta de registro de metodologia sobre como realizar pesquisa histórica explica o desafio da integração entre a análise histórica e a organização (Wadhwani \& Bucheli, 2014).

Este tem sido o desafio de autores em outras investigações (Dias \& Becker, 2013; Silva, Souza \& Silva, 2017) que, de alguma forma, também serviu de motivação para a escrita deste artigo. Do mesmo modo análise temática também contribuiu com a escolha amparada pelos paradigmas interpretacionistas, nos quais as organizações são processos que surgem das ações intencionais das pessoas, individualmente ou em harmonia com outras.

\section{Considerações Finais}

Este artigo apresentou pistas sobre a operacionalização da técnica de análise temática conforme as características e sugestão de fases de análise descritas por Braun e Clarke (2006), a partir de pesquisas realizadas. A proposta não foi comparar a outras técnicas ou abordagens, não havendo a defesa aqui de que AT seria a melhor ou mais simples das possibilidades. Exploramos as suas características como mais uma opção para análise no sentido de ajudar a decisão e escolha pelo pesquisador, que deve se sentir confiante com sua aplicação, ou seja, com conhecimento dos limites da técnica, e, evidentemente, seguro que este será o melhor caminho para as descobertas previstas na pesquisa.

Se a história for coerente e lógica, os leitores são capazes de viajar facilmente através os mundos de desenvolvedores "temas" e decidir por si mesmos se os temas são esforços legítimos de pesquisa. Os autores Braun e Clarke (2006), Cunliffe (2011); Vaismoradi et al. (2013) reconhecem a história desenvolvida com base em temas como estratégia tomada de "sentido", não de "verdade(s)". 
A pesquisa A explorou falas e contextos de sujeitos tratando de suas escolhas e sentimentos e a flexibilidade da análise temática deu a resposta imediata que o pesquisador precisava de como tratar aqueles dados nem sempre marcados por palavras, nem sempre dentro de pensamentos lineares, nem sempre ditos com a mesma simbologia das palavras faladas.

A partir da realização da Pesquisa B, constatou-se que a Análise Temática contribui para o desenvolvimento de pesquisas de cunho histórico e interpretativista, um desafio epistemológico e metodológico característico dos estudos desta natureza no campo da Administração: como realizar pesquisa histórica (metodologia), considerando o desafio de integração entre a análise histórica e a organização (Wadhwani \& Bucheli, 2014). Este tem sido o desafio dos autores em outras investigações que, de alguma forma, também serviu de motivação para a escrita deste artigo.

A Análise Temática se apresentou como uma técnica de análise qualitativa caracterizada pela flexibilidade, por ser essencialmente independente de uma teoria ou epistemologia específica e que pode ser aplicada com uma variedade de abordagens teóricas e epistemológicas. Este aspecto que contribuiu para adoção dessa técnica na análise dos dados da Pesquisa $\mathrm{B}$, pois esta investigação tinha um referencial teórico parcial mesmo após o término da pesquisa empírica, o que configurou no desenho indutivo da pesquisa.

Embora o engajamento com a literatura existente antes da coleta de dados seja característica da maior parte dos métodos qualitativos, é fortemente sugerido pelos autores Braun e Clarke (2006), Godoi e Balsini (2010), Deslauriers e Kérisit (2012) que a revisão da literatura em profundidade seja adiada até que a coleta da maioria dos dados seja concluída para evitar introdução de preconceito e noções percebidas. A decisão na Pesquisa B foi por uma parada na revisão bibliográfica e viajar pela empiria.

Essa viagem permitiu que temas surgissem naturalmente a partir dos dados empíricos, durante a coleta e a análise, desinibidas por quadros teóricos existentes e/ou associados à hipótese. Portanto, manter a revisão de literatura em suspenso, a fim de realizar a análise indutiva e o desenvolvimento de tema, embora possa parecer difícil é totalmente factível (Braun \& Clarke, 2006; Godo \& Balsini, 2010; Deslauriers \& Kérisit, 2012). Hoje reconhece-se que a riqueza deste estudo histórico-organizacional está neste caminho de idas e vindas. Fica aqui a sugestão para estudos futuros.

Ressalta como contribuições principais o uso da AT como uma técnica flexível para os Estudos Organizacionais e suas diversas abordagens epistemológicas. Ainda, no âmbito das pesquisas qualitativas, se apresentou como um suporte metodológico coerente e relevante, na análise dos dados da pesquisa histórica em organizações, em particular. Assim, vislumbra-se que a análise temática também contribuirá para pesquisas amparadas pelos paradigmas interpretacionistas, nos quais as organizações são processos que surgem das ações intencionais das pessoas, individualmente ou em harmonia com outras. Elas interagem entre si na tentativa de interpretar e dar sentido ao seu mundo.

A literatura de origem da análise temática é a área de saúde, ao tempo que se apresenta como limitação ao estudo realizado, pois a referida área guarda suas particularidades metodológicas em relação ao campo da administração, também se apresenta como desafio e grandes possibilidades de discussão para a pesquisa qualitativa, como ocorreu com um dos autores durante evento internacional de pesquisa qualitativa, o qual possibilitou a discussão tanto no campo da saúde e das organização, enriquecendo o debate da sessão.

A título de sugestão para trabalhos futuros, propõe-se o uso da Análise Temática como técnica de análise, principalmente em pesquisas que envolvem alto nível de subjetividade envolvidos, oferecendo novas possibilidades na construção do conhecimento da área, incentivando uma certa ousadia de produzir conhecimento criando novos caminhos de coleta e análise, e a pensar e fazer pesquisa "fora da caixinha".

Agradecimentos. A Universidade Federal de Sergipe pelo apoio institucional e ao CNPq pelo apoio financeiro que possibilitou custear as despesas da pesquisa B. 


\section{Referências}

Alhojailan, M. I. (2012). Thematic analysis: A critical review of its process and evaluation. West East Journal of Social Sciences, 1(1), 39-47.

Bachelard, G. (2010). A epistemologia. São Paulo: Edições 70.

Braun, V., \& Clark, V. (2006). Using thematic analysis in psychology. Qualitative Research, 3(2), p. 77-101.

Corley, K. G., \& Gioia, D. A. (2011). Building theory about theory building: what constitutes a theoretical contribution? Academy of management review, 36(1), 12-32.

Cunliffe, A. L. (2011). Crafting qualitative research: Morgan and Smircich 30 years on. Organizational research methods, 14(4), 647-673.

Denzin, N. K., \& Lincoln, Y. S. (2006). O planejamento da pesquisa qualitativa: teorias e abordagens. In O planejamento da pesquisa qualitativa: teorias e abordagens.

Deslauriers, J. P., \& Kérisit, M. (2012). O delineamento da pesquisa qualitativa. IN: POUPART, Jean. Et al. A pesquisa qualitativa: enfoques epistemológicos e metodológicos. $3^{\text {a }}$. ed. Petrópolis: Vozes.

Dias, J., \& Becker, V. G (2013). Abordagem histórico-longitudinal em pesquisas de administração estratégica. Revista Gestão Organizacional. V. 6(3),p. 37-49

Godoi, C. K., \& Balsini, C. P. V. (2010). A pesquisa qualitativa nos estudos organizacionais brasileiros: uma análise bibliométrica. In: GODOI, C. K.; BANDEIRA-DE-MELO, R.

G, C. (2013). Spontaneous images in the mind: a thematic analysis of Psychoanalytic Literatura on Psychotherapits. Retrieved January, 10, 2016.

King, N., \& Brooks, J. (2018). Thematic analysis in organisational research. The SAGE handbook of qualitative business and management research methods: methods and challenges.

Marconi, M. A., \& Lakatos, E. M. (2006). Fundamentos de metodologia cientifica. 6. ed. São Paulo: Atlas.

Silva, M. R. (2017). História organizacional da ENAP: uma análise dos papéis desempenhados e das competências desenvolvidas. (tese de doutoramento). Universidade Federal da Bahia, Escola de Administração, Salvador.

Silva, M. R., Souza, R. K. S., \& Silva, M.A.M (2017) Pequenas Ousadias Historiográficas Contra a Timidez. dos Estudos Históricos-Organizacionais Brasileiros: uma discussão sobre escolhas epistemológicas, teóricas e metodológicas. Anais eletrônicos do Encontro Dos Progrmas de Pós-Graduação em Administração. São Paulo, SP, Brasil,41

Tracy, S. J. (2010). Qualitative quality: Eight "big-tent" criteria for excellent qualitative research. Qualitative inquiry, 16(10), 837-851.

Vaismoradi, M., Jones, J., Turunen, H., \& Snelgrove, S. (2016). Theme development in qualitative content analysis and thematic analysis.

Vaismoradi, M., Turunen, H., \& Bondas, T. (2013). Content analysis and thematic analysis: Implications for conducting a qualitative descriptive study. Nursing \& health sciences, 15(3), 398-405.

Vergara, S. C. (2010). Métodos de pesquisa em Administração. 4. ed. São Paulo: Atlas.

Vizeu, F. (2010). Potencialidades Da Análise Histórica Nos Estudos Organizacionais Brasileiros. RAERevista de Administração de Empresas, v.50(1), 37-47.

Wadhwani, D., \& Bucheli, M. The Future of Past in Management and Management and Organization Studies. In. Organizations in Time. United Kindgon: Oxford, 2014. p. 124-146. 